Viqar Abmed 123

Note:

\title{
Public Policy: The Implementation Gap
}

\section{Viqar Ahmed}

Policy formulation and implementation are the chief, though not the only, business of a modern government, implying exercise of its power. In a democracy the people themselves grant permission to the government to exercise power in their name. Thus through the democratic process power is transformed into legitimate authority. However, there is a feeling that a policy, formulated through due procedures at the highest echelons of the government, is sometimes not implemented in the same spirit or in the same way as was originally intended by the policy makers. Thus there If need to locate and identify the points where such lapses take place.

A policy implies a systemised attack on a certain specific problem or a methodical way of dealing with a certain sector. Usually all government action is taken, or is supposed to be taken, under the directions of a certain overall policy. Thus there are policies relating to sectors e.g. agriculture, industry, trade, social sectors etc., implying a framework of continuous government action. But sometimes it is felt that in a certain area, routine measures have failed and government departments in their ordinary day-today functioning arc unable to cope with the entire magnitude of a particular problem. Such cases relate to crisis management or making a frontal attack on a long festering problem e.g. disaster management, law and order breakdown, urgent need for export promotion, attracting foreign investment, shortages of essential goods, etc. Here a number of departments are involved in meeting a certain situation and coordination is needed between them so that the role of each department is defined and functions clearly spelt out. A policy is needed in such situations as an extraordinary way to meet that situation. A policy contains the following steps: (i) identification of a problem or a problem area; (ii) objectives to be achieved within a certain time frame, (iii) specific measures to achieve the objectives; (iv) suitable adjustments in other policies to make the new measures more effective and to remove anomalies and contradictions; (v) defining responsibility for implementation, (vi) designating staff and materials; (vii) publicity campaign to convince government personnel and the general public about justification for such policy action.

The orthodox assumption that policy making within a government is done by the political sector while implementation is the function of the bureaucracy is hardly relevant in this country. Policy making may now be described as a joint exercise conducted by the political and administrative 
leadership. A problem may be identified and its relative priority may be determined by the political leadership while preparing a set of alternatives to deal with the problem. This may be the function of the administrator. Politicians representing the people may choose an alternative which in their opinion people would prefer and for which people would be willing to pay the cost. It is for the political leadership to ensure that the cost-benefit ratio of a certain policy alternative is in line with the desires of the people. For example, in the situation concerning the scarcity of sugar in 1996-97, there were obviously only three alternatives: to raise the production of sugar or import sugar from abroad or cut down its consumption through rationing. Only representatives of the people could be in a position to judge as to which of the three alternatives would be acceptable to the public, and for which the public would be willing to pay the price since each alternative carried its own price tag. The administration has to work out the ways and means to give the policy concrete shape before the field staff or the concerned departments are called upon to implement the policy.

Thus policy formulation and implementation are separate functions. Each task needs a certain degree of specialised knowledge and experience. By the very nature of the tasks, the policy formulation body must have supreme control and authority over policy implementing agencies.

Successful implementation of policy thus requires a well-defined formal relationship between the policy making and policy implementing agencies. There is need for institutional arrangements for consultation with the field and operative staff while the mechanism of a certain policy is being formulated in order that problems in the field are kept in view. Similarly, the policy makers must have a built-in system of progress and evaluation of policy implementation at each stage so that if there are any bottlenecks, these can be removed before the next phase is undertaken.

Advance planning is most essential. Sometimes governments are impatient and regard the time spent on advance planning as wastage. But in fact this is essential in order to reduce greater wastage, which may take place if the policy turns out to be misconceived or mistaken. Past experience and the lessons learnt in earlier attempts, if any, would provide the right setting to frame a policy for the future and guarantee a certain amount of continuity. Advance planning includes data collection, processing and checking the authority of the collected data, as well as feasibility testing.

A sound policy can be formulated if it is based largely on inductive analysis. Induction means proceeding from the particular to the general. This is also akin to the historical method in which conclusions are based on facts and figures collected over a certain period of time covering various 
aspects of the problem. However, the tendency in developing societies is to base policy formulation on a deductive approach i.e. proceeding from the general to the particular. Certain assumptions are made which may or may not be supported by facts and figures. These assumptions may be based on the impressions and prejudices of the policy makers. In an inductive approach the process no doubt is more complicated and difficult but it minimises the risk of mistakes and wrong conclusions drawn from incorrect assumptions.

There are examples where governments have been deceived by their own anxiety and enthusiasm which has led to the collection of incorrect or inflated data. Sometimes, for example, the government is extremely enthusiastic about increasing wheat production. Anticipating this, local officials responsible for the collection of data may be tempted to inflate the figures of wheat output. An anxious government may gratefully accept these figures and act as if these were correct. Thus objectivity is essential not only for officers and staff responsible for data collection but also for those who give them directions.

A policy operates within a socio-economic and political context and therefore, the government has to see whether the social climate in the country is suitable for that particular policy. If such a climate does not exist, the government must asses its own capability of creating this climate. In case this is also not found to be possible, the policy must be given up as being premature.

There is a general impression that open discussion and diversity of opinion about a certain problem leads to "confused thinking". This is a byproduct of the deductive approach since diversity of opinions may cast doubts on certain basic presumptions. It is time to do away with this cliche. A policy, before it is finalised, must be thoroughly discussed both within and outside the government. If it is based on sound logic and reliable data, discussion would only contribute to greater clarity of thinking.

As regards physical arrangements for policy implementation, the policy makers may sometimes in their enthusiasm, set unrealistic targets and objectives to be achieved by those who are responsible for implementation. This leads to greater tension between policy makers and those responsible for implementation. Many policies fail because values of the formulators of the policy differ from the values of the operative staff. Thus the policy suffers from lack of understanding. Communication between the high ups and those at the lower level may also break down. As such, one of the fundamental requirements of successful policy implementation is motivating the people and convincing them about the ends of the policy. The staff 
must be convinced that the government is sincere and the objectives of the policy are genuine and desirable and that it is not trying only to score certain propaganda points in the short-run. Here the example of the Basic Democracy system may be mentioned. While the objectives officially forwarded were to bring the people closer to the government and to give broader based representation to the people at large, the policy failed to convince the nation. The impression lingered on that it was a device for perpetuating the regime. This happened inspite of the massive publicity campaign launched in its favour by the powerful mass-communication media.

In many cases there is a provision in principle for associating the operative staff in policy formulation. But it is not actually practised. This creates distance, jealousy and contempt between the formulators of the policy. Each policy is bound to produce certain conflicts of interest and as such it is bound to be resisted by those who are adversely affected. Moreover, certain resistances exist within each society on the basis of beliefs and prejudices. Thus before a policy is to be implemented such resistances should be taken into consideration. In order to break these resistance, responsibility has to be ascertained. Sometimes a government may carry out a policy without having to face resistance. The burden in such cases is shifted to the field staff who may not be fully equipped to deal with such resistance and in many cases they themselves may be influenced by the same resistance or prejudices. For example, in the family planning programme the field staff has at times proved to be incapable of removing centuries-old prejudices against it. It is for the political sector to deal with such basic cultural prejudices with the help of its resources and influence in the minds of the people. Finally, one basic flaw in our policy making process is the extreme degree of inflexibility of the policy structure. Once a policy is made, it becomes a matter of prestige for the policy makers to carry it out even though subsequent experience in the field or changing socio-economic conditions may necessitate certain modifications or alterations. The policy maker must by nature be flexible, open-minded and willing to correct himself if circumstances prove certain of his assumptions to be faulty or conclusions to be inaccurate. A policy by itself must be flexible so that it is subject to constant modifications and re-modifications. The policy maker must also know when the policy has become outdated or has lost its validity. There are examples in Pakistan of policies which have been continued even after outliving their utility, e.g. the Export Bonus Scheme introduced in 1959. The scheme should have been abolished in the mid-sixties, as it had become a major factor in creating tensions between East Pakistan and West

Pakistan. But many powerful interest groups, earning 
large unearned incomes under its auspices, persuaded the Ayub regime that its withdrawal would hurt the prestige of the government.

Flaws in policy formulation, monitoring and coordination are an everyday occurrance. Policies affect the social, political and economic structure in innumerable ways. Policies are, in the final analysis, the products of compromises arrived at between different power centres. Policies, in the span of their life cycles, must contend with pressures from various social and economic groups, and also different trends of thought and opinion. Such interaction has as much of a chance of distorting the policy profile as that of enrichment of its intellectual content.

Quite often, interest groups find it more convenient to apply pressure not during the formulation phase but during its implementation. But in addition to such pressures, there are many other and more objective factors, which may necessitate changes in the basic thrust and complexion of the policy. A changing economic and political situation, necessitating adjustments in objectives and priorities, shortfall in resources, the inefficiency of the implementing agencies, corruption and a changing national and international environment may in great part be responsible for the creation of implementation gaps.

Thus, within reasonable limits, implementation hiatuses should be accepted as a part of life. But if such gaps widen across the board and become typical of all major policy initiatives, it indicates loss of government control over the affairs of state, extremely high levels of inefficiency and corruption, and the predominance of interest groups in policy making and implementation in lieu of objective decision-making in the overall national interest. 
128 The Lahore Journal of Economics, Vol.2, No.2

\section{References}

Callahan, Daniel \& Bruce Jennings, 1983, Ethics, the Social Sciences and Policy Analysis Plenum Press, New York.

Dunn, William N. 1994, Public Policy Analysis: An Introduction, Prentice Hall, New Jersey.

Habib, Hasan, 1974, Public Policy Analysis and Development: Country Paper on Pakistan, Two Volumes, ACDA, Kuala Lumpur.

Hogwood, Brian W.\& B. Guy Peters, 1983, Policy Dynamics, St. Martin's Press, New York..

Wadhwa, Sharan D. 1977, Some Problems of India's Economic Policy, Tata McGraw Hill. New Delhi. 